\title{
CHARACTERIZATIONS OF CHAOTIC ORDER ASSOCIATED WITH THE MOND-SHISHA DIFFERENCE
}

\author{
JUN ICHI FUJII AND YUKI SEO
}

Abstract. Recently, Yamazaki showed new order preserving operator inequalities on the usual order and the chaotic order by estimating the lower bound of the difference. Mond and Shisha gave an estimtate of the difference of the arithmetic one to the geometric one, as a converse of the arithmetic-geometric mean inequality. In this paper, by means of the Mond-Shisha difference, we shall put another interpretation on a characterization of the chaotic order associated with the difference by Yamazaki: If $A>0, M I \geqslant B \geqslant m I>0$ and $h=\frac{M}{m}>1$, then $\log A \geqslant \log B$ is equivalent to

$$
A^{p}+D\left(m^{p}, M^{p}\right) I \geqslant B^{p} \quad \text { for all } p>0,
$$

where

$$
D\left(m^{p}, M^{p}\right)=\theta M^{p}+(1-\theta) m^{p}-M^{p \theta} m^{p(1-\theta)} \quad \text { and } \quad \theta=\log \left(\frac{h^{p}-1}{p \log h}\right) \frac{1}{p \log h} .
$$

Moreover, inspired by Yamazaki's work, we shall make an attempt to clarify distinction between the usual order and the chaotic order by using the Furuta inequality. Among others, we show the following parametrized order preserving operator inequalities associated with the difference: If $A>0$ and $M I \geqslant B \geqslant m I>0$, then for each $\delta \in[0,1]$

$$
A^{\delta} \geqslant B^{\delta} \quad \text { if and only if } \quad A^{p+\delta}+\frac{1}{m^{r}} C\left(m^{r+\delta}, M^{r+\delta}, \frac{p+r+\delta}{r+\delta}\right) I \geqslant B^{p+\delta} \text { for } p, r>0
$$

where the case $\delta=0$ means the chaotic order.

Mathematics subject classification (2000): 47A30, 47A63.

Key words and phrases: usual order, chaotic order, Furuta inequality, Specht's ratio.

\section{REFERENCES}

[1] J. I. FUJII, T. FURUTA, T. YAMAZAKI AND M. YANAGIDA, Simplified proof of characterization of chaotic order via Specht's ratio, Sci. Math., 2(1999), 63-64.

[2] J. I. FUJII, S. IZUMINO AND Y. SEO, Determinant for positive operators and Specht's theorem, Sci. Math., 1(1998), 307-310.

[3] J. I. FUJII AND Y. SEO, Determinant for positive operators, Sci. Math., 1(1998), 153-156.

[4] M. FUJII, Furuta's inequality and its mean theoretic approach, J. Operator Theory, 23(1990), 67-72.

[5] M. FUJII, T. FURUTA AND E. KAMEI, Furuta's inequality and its application to Ando's theorem, Linear Algebra Appl., 179(1993), 161-169.

[6] M. Fuji, S. Izumino, R. NAKAmoto And Y. SEO, Operator inequalities related to Cauchy-Schwarz and Hölder-McCarthy inequalities, Nihonkai Math. J., 8, No. 2(1997), 117-122.

[7] M. FuJII, J. F. JIANG AND E. KAMEI, Characterization of chaotic order and its application to Furuta inequality, Proc. Amer. Math. Soc., 125(1997), 3655-3658.

[8] M. FUJII, E. KAMEI AND Y. SEO, Kantorovich type operator inequalities via grand Furuta inequality, Sci. Math., 3(2000), 263-272. 
[9] T. FurutA, $A \geqslant B \geqslant 0$ assures $\left(B^{r} A^{p} B^{r}\right)^{1 / q} \geqslant B^{(p+2 r) / q}$ for $r \geqslant 0, p \geqslant 0, q \geqslant 1$ with $(1+2 r) q \geqslant p+2 r$, Proc. Amer. Math. Soc., 101(1987), 85-88.

[10] T. FURUTA, Elementary proof of an order preserving inequality, Proc. Japan Acad., 65(1989), 126.

[11] T. FURUTA, Applications of order preserving operator inequalities, Operator Theory: Advances and Applications, 59(1992), 180-190.

[12] T. FURUTA, Operator inequalities associated with Hölder-McCarthy and Kantorovich inequalities, J. Inequal. Appl., 2(1998), 137-148.

[13] T. FuRUTA, Results under $\log A \geqslant \log B$ can be derived from ones under $A \geqslant B \geqslant 0$ by Uchiyama's method - associated with Furuta and Kantorovich type operator inequalities - , Math. Inequal. Appl., 3(2000), 423-436.

[14] E. KAMEI, A satellite to Furuta's inequality, Math. Japon, 33(1988), 883-886.

[15] E. KAMEI, Interpolations between the operator and chaotic orders via Kantorovich type operator inequalities, Sci. Math., 3(2000), 257-262.

[16] Ky FAN, Some matrix inequalities, Abh. Math. Sem. Univ. Hamburg, 29(1966), 185-196.

[17] J. Mićić, Y. SEO, S.-E. TAKAHASI AND M. TOMINAGA, Inequalities of Furuta and Mond-Pečarić, Math. Inequal. Appl., 2(1999), 83-112.

[18] B. MOND AND O. SHISHA, Difference and ratio inequalities in Hilbert space, "Inequalities II", (O. Shisha, ed.). Academic Press, New York, 1970, 241-249.

[19] O. SHISHA AND B. Mond, Bounds on difference of means, "Inequalities", (O. Shisha, ed.). Academic Press, New York, 1967, 293-308.

[20] W. SPECHT, Zur Theorie der elementaren Mittel, Math. Z., 74(1960), 91-98.

[21] K. TANAHASHI, Best possibility of the Furuta inequality, Proc. Amer. Math. Soc., 124(1996), 141-146.

[22] T. YAMAZAKI, An extensuin of Specht's theorem via Kantorovich inequality and related results, Math. Inequal. Appl., 3(2000), 89-96.

[23] T. YAMAZAKI, Further characterizations of chaotic order via Specht's ratio, Math. Inequal. Appl., 3(2000), 259-268.

[24] T. YAMAZAKI AND M. YANAGIDA, Characterizations of chaotic order associated with Kantorovich inequality, Sci. Math., 2(1999), 37-50.

[25] M. YAnAgIDA, Some applications of Tanahashi's result on the best possibility of Furuta inequality, Math. Inequal. Appl., 2(1999), 297-305. 